\title{
Deaths and Hospital Injuries Due to the 1999 Taiwan Earthquake
}

\author{
Yen-Hsiung Liao \\ Department of Health Sciences, School of Public Health, Kaohsiung Medical University, Kaohsiung, Taiwan \\ Email: bany0309@yahoo.com.tw
}

Received October 4, 2012; revised November 15, 2012; accepted November 27, 2012

\begin{abstract}
To assess risk factors associated with deaths and injuries in a major earthquake area. First, we used the official data including 824 seismic deaths, 271 serious injuries, and 302 moderate injuries to elucidate and compare the demographic, structural, and injury characteristics among the three groups. Secondly, a population based case-control study was conducted to examine how structural factors, medical assistance, personal characteristic, and behavior and preparedness contributed to injury. The age-specific proportions of the three groups were similar and higher in the elderly population. Severity of injuries was proportional to the proportion of completely collapsed houses. Fracture was the most frequently observed among the serious injuries and moderate injuries. Head injury was the major body site caused by the collapsed houses for the seismic deaths. In a case-control study, people who were trapped (adjusted OR $=12.31,95 \%$ CI: 6.29 24.28) had the greatest risk of serious injuries, followed by those who were illiterate, in completely collapsed houses, and experienced unprepared flares. This study reveals that improvement in anti-seismic construction, head protect, and literacy education could decrease the effect of disaster. Further, using a flashlight to see in the dark, and moving slowly rather than running should be rigorously recommended as common-sense responses.
\end{abstract}

Keywords: Earthquake; Anti-Seismic; Head Protection; Literacy Education

\section{Introduction}

On 21 September 1999, at $1 \mathrm{~h} 47 \mathrm{~m}$, an earthquake of magnitude 7.3 on the Richter scale struck the central area of Taiwan [1]. As a result of the earthquake, more than 100,000 houses were collapsed, 2347 people died, and more than 8000 were injured all over the island, of whom approximately 700 were seriously injured [2].

A number of past investigations of related morbidity and mortality have reported associations of deaths and injuries with seismic factors [3-7], structural factors [8-13], injury characteristics [14-17], personal characteristics [1823], and victim behavior and preparation [24-35].

The ground motion intensity correlated with poor antiseismic houses increased the risk of death as found in the 1999 Taiwan earthquake $[5,13,36]$. The mortality was higher among the female, disabled, and the elderly groups $[5,15,22]$. Chan suggested that precise disaster planning and management were necessary to improve the disaster responses [12]. Two studies described about the characteristics of non-fatal injuries for the victims of the disaster $[32,34]$. The victims were also more vulnerable to have posttraumatic outcomes following the 1999 Taiwan earthquake [37-44]. The suicide trends declined after two years by the proving strengthened psychiatric services
[45]. No further studies have discussed the relationship between injury characteristics and victim behavior and response in the emergency period. To improve preparedness for earthquakes, we must rely on more knowledge about factors related to deaths and injuries. The goal of the first investigation was to understand the roles of structural, injury, and demographic characteristics played in earthquake-related deaths and injuries. The second investigation using base of a case-control study, was to understand of structural factors, medical assistance, personal characteristics, victim behavior and preparedness that contributed to physical injury.

\section{Methods}

\subsection{Study Area and Subjects}

Selected the Nantou County as the area of study subjects because the most severe destruction occurred in Nantou County that near the epicenter. Moreover 11 out of the total 13 townships in Nantou were within the strongest earthquake intensity area (earthquake intensity $7=$ peak ground acceleration $>400$ gal). There were 824 people killed, and 2421 people injured. Age-specific population data from August 1999 were used as the standard population. 


\subsection{Collapsed Houses, Human Deaths and Injuries}

Post-earthquake inspection data were obtained from the Architecture and Building Research Institute, Ministry of Interior. On the basis of architect-defined criteria, destroyed houses were categorized as either completely collapsed or partially collapsed. The degree of housing damage was used in many post-earthquake welfare and funding programs after the 1999 Taiwan earthquake.

Computerized data on earthquake-related deaths were retrieved from the Central Taiwan Office, Department of Health. These data included date of birth, gender, date of death, location, and cause of death coded by the International Classification of Diseases, Ninth Revision (ICD9).

The earthquake-related injuries were obtained from the Department of Public Health Bureau, Nantou County Government. These data were grouped according to ICD9 guideline, the relevant ICD codes were showed in the appendix.

There were two documents including serious injury and moderate injury. The serious injuries were defined as those patients whose injuries required hospitalization care with an extend follow-up of more than 30 days. The moderate injuries were defined as those patients whose injuries required hospitalization care less than or equal to 30 days. The local government provided 200 thousand Taiwan dollars for every serious injury and provided 50 thousand Taiwan dollars for every moderate injury respectively.

\subsection{Case-Control Study}

This study was begun in April 2002 and finished in December 2002. From detailed rosters of 271 severe injuries, 120 randomized cases were defined as study cases. For each of the cases, we selected a non-hospitalized control from a neighboring household. An effort was made to match the controls and cases according to sex and age within \pm 5 years. The ratio of cases versus controls was 1:2. After the variables of interest had been defined, a set of questions was formulated and a questionnaire was developed to a structural questionnaire. Personal interviews with structural questionnaire were conducted with the subjects by trained interviewers. The questionnaire was pre-tested on a sample of 15 cases and 15 controls, and validated by 8 experts. The questionnaire included structural information (completely collapsed, inside house, sleep in house, live alone, trapped), medical assistance (trapped time, received first medical care after extrication, rescuer of trapped victims), personal characteristics (illiteracy, unemployment, major disease before the earthquake, other family hurt), and behavior and preparedness (drill for disaster before the earthquake, evacuation road, put heavier objects in low places, put objectives in the doorway, prepare fire extinguishers, prepare flares, number of export escapes) following the earthquake. These questions were answered in a form of "yes" or "no".

\subsection{Statistic}

These analyses focus on the types and body sites of injuries incurred by the residents as a result of the earthquake. Bivariate analyses were conducted to identify major trends among the three groups during the earthquake. Crosstabs with chi-square analysis were used to examine associations between variables. A conditional logistic regression analysis was adopted to assess the odds ratio of the statistically significant variable used in the case-control study. All variables were dichotomous without missing data. This analytic process was performed by using SPSS statistical software (SPSS Inc., Chicago, IL) for Window.

\section{Results}

Of all the 824 seismic deaths, 652 (79.1\%) of the people died in their own houses, $83(10.1 \%)$ died on their way to referral hospitals, 18 (2.2\%) died in the referral hospitals, and $71(8.6 \%)$ died in the evacuation area or the data were missing. There were $89.2 \%$ of the seismic deaths were not admitted to the emergency department of a hospital.

The injury documentation shows that a total of 2421 injuries were admitted to hospitals by transportation, 83 (3.4\%) died on their way to referral hospitals, 591 (24.4\%) required hospitalization and 1747 (72.2\%) sustained only minor injury and were discharged after wound treatment. Among the 591 hospitalized injuries, $302(51.1 \%)$ were defined moderate injuries, 271 (45.9\%) were defined as serious injuries, and $18(3.0 \%)$ were died in hospitals.

\subsection{Demographic and Structural Characteristics}

There were 545,181 people including 284,841 (52.2\%) males and 260,340 (47.8\%) females in the study area. Table 1 compares the basic demographic and collapsed houses information for the reported deaths, serious injuries, and moderate injuries following the Chi-Chi earthquake. Females were more likely to report death and injury than males but not significantly different $(\mathrm{p}<0.05)$. From the distribution of age-specific death rates, it was found that the proportion of 65 years of age and older among the three injured subgroups were similar (death: $37.0 \%$, serious injuries: $37.6 \%$, moderate injuries: $36.1 \%$ ). However, these proportions were all significantly higher than the proportion of people of 65 years of age and older in the general population (10.1\%) (deaths: odds ratio 
Table 1. Demographic and building characteristics of deaths and non-fatal injuries caused by the Chi-Chi earthquake, Nantou, Taiwan, 1999.

\begin{tabular}{|c|c|c|c|c|}
\hline Characteristic & Death & Serious injury & Moderate injury & Population \\
\hline Number & 824 & 271 & 302 & 545,180 \\
\hline Male $\%$ & 47 & 50 & 44 & 52 \\
\hline Female $\%$ & 53 & 50 & 56 & 48 \\
\hline \multicolumn{5}{|l|}{ Age } \\
\hline$\leq 14$ yrs $\%$ & 14.7 & 5.2 & 1.6 & 21.3 \\
\hline $15-64$ yrs \% & 48.3 & 57.2 & 62.3 & 68.5 \\
\hline$\geq 65 \mathrm{yrs} \%$ & 37 & 37.6 & 36.1 & 10.1 \\
\hline OR & 5.29 & 5.52 & 5.06 & 1 \\
\hline $95 \%(\mathrm{CI})$ & $(2.45-11.41)$ & $(2.56-11.89)$ & $(2.34-10.92)$ & \\
\hline \multicolumn{5}{|l|}{ Houses collapsed } \\
\hline No (\%) & $41(5.0)$ & $30(11.1)$ & $36(11.9)$ & \\
\hline Yes (\%) & $783(95.0)$ & $241(88.9)$ & $266(88.1)$ & \\
\hline Completely & 740 & 154 & 92 & \\
\hline Partially & 43 & 87 & 174 & \\
\hline OR & 32.55 & 3.35 & 1 & \\
\hline $95 \%(\mathrm{CI})$ & $(21.86-48.46)$ & $(2.33-4.82)$ & & \\
\hline
\end{tabular}

$\mathrm{OR}=5.29,95 \%$ confidence interval $(\mathrm{CI}): 2.45-11.41$ serious injuries: $\mathrm{OR}=5.52,95 \% \mathrm{CI}: 2.56-11.89$; moderate injuries: $\mathrm{OR}=5.06,95 \% \mathrm{CI}: 2.34$ - 10.94).

The proportions of collapsed houses of the deaths $(783 / 824=95.0 \%)$, serious injuries $(241 / 271=88.9 \%)$, and moderate injuries $(266 / 302=88.1 \%)$ were similar. For the collapsed houses, the completely collapsed occupied $94.5 \%(740 / 783)$ of the deaths, $63.9 \%(154 / 241)$ of the serious injuries, and $34.6 \%(92 / 266)$ of the moderate injuries, respectively. Compared to the moderate injuries, the crude odds ratios of completely collapsed houses were 32.55 (95\% CI: 21.86 - 48.46) for deaths, and 3.35 (95\% CI: 2.33 - 4.82) for serious injuries.

\subsection{Injury Characteristics}

Table 2 shows data related to the injury characteristics of deaths and non-fatal injuries. The distribution of types of injuries between the deaths and seriously injuries was different. Intracranial and internal injuries were the most frequently observed (43.4\%), followed by asphyxiation, fracture, and early complication of trauma and unspecific injury $(6.3 \%)$ of the deaths. Fracture $(49.4 \%)$ was the most common type of injury, followed by open wounds, early complication of trauma and unspecific injury $(12.9 \%)$, and burns $(8.8 \%)$ of the serious injuries. Fracture $(42.7 \%)$ was also the most frequently observed in- jury of the moderate injuries, followed by early complication of trauma and unspecific injury $(27.8 \%)$, and open wounds $(11.9 \%)$.

The prevalence of burns of the serious injuries $(8.8 \%)$ was significantly higher than the prevalence of burns of the moderate injuries $(1.0 \%)(\mathrm{OR}=9.79,95 \% \mathrm{CI}: 1.22$ 78.8).

The distribution of injured body sites among the deaths and non-fatal injuries in collapsed houses was shown in Table 3. Head was the major body site of deaths (37.8\%). However, the major body site of non-fatal injuries was the extremities $(32.5 \%$ of serious injuries, and $38.3 \%$ of moderate injuries). The proportion of head injury of the deaths was significantly higher than the proportion of head injury of the serious injuries $(5.0 \%$, OR $=11.60$, $95 \%$ CI: $6.38-21.10)$, and of the moderate injuries $(6.4 \%$, OR $=8.90,95 \%$ CI: 5.33 - 14.96), respectively. There was no difference in the proportion of head injury between the serious injuries and the moderate injuries $(\mathrm{OR}=0.77,95 \% \mathrm{CI}: 0.36-1.64)$. The proportion of neck and trunk injury of the deaths $(13.3 \%)$ was significantly lower than the proportion of neck and trunk injury of the serious injuries $(21.6 \%, \mathrm{OR}=0.56,95 \% \mathrm{CI}: 0.38-0.81)$. There was no difference in the proportion of neck and trunk injury between the moderate injuries (16.5\%) and serious injuries $(\mathrm{OR}=1.39,95 \% \mathrm{CI}: 0.89-2.17)$, and the 
Table 2. Types of injuries among the deaths and non-fatal injuries caused by the Chi-Chi earthquake, Nantou, Taiwan, 1999.

\begin{tabular}{cccc}
\hline Characteristic & Death & Serious injuries & Moderate injuries \\
\hline No (\%) & $824(100)$ & $271(100)$ & $302(100)$ \\
$\begin{array}{c}\text { Intracranial and } \\
\text { internal injuries } \\
\text { Asphyxiation } \\
\text { Fracture }\end{array}$ & $357(43.4)$ & $7(2.6)$ & 0 \\
$\begin{array}{c}\text { Early complication } \\
\text { of trauma and } \\
\text { unspecific injury }\end{array}$ & $277(33.6)$ & 0 & $130(42.7)$ \\
Open wounds & $67(8.1)$ & $35(12.9)$ & $83(27.5)$ \\
Burns & $52(6.3)$ & $54(19.9)$ & $35(11.9)$ \\
Others & $1(0.1)$ & $24(8.8)$ & $3(1.0)$ \\
\hline
\end{tabular}

Table 3. Injured body sites among deaths and non-fatal injuries in the collapsed houses caused by the Chi-Chi earthquake, Nantou, Taiwan.

\begin{tabular}{|c|c|c|c|}
\hline Body site & Death & Serious injuries & Moderate injuries \\
\hline No $(\%)$ & $783(100)$ & $241(100)$ & $266(100)$ \\
\hline Head & $296(37.8)$ & $12(5.0)$ & $17(6.4)$ \\
\hline \multirow{2}{*}{ OR $(95 \% \mathrm{CI})$} & $11.60^{*}(6.38-21.10)$ & 1 & 1 \\
\hline & $8.90^{*}(5.33-14.96)$ & $0.77(0.36-1.64)$ & 1 \\
\hline Neck and trunk & $144(13.3)$ & $52(21.6)$ & $44(16.5)$ \\
\hline \multirow{2}{*}{ OR $(95 \% \mathrm{CI})$} & $0.56^{*}(0.38-0.81)$ & 1 & \\
\hline & $0.77(0.53-1.13)$ & $1.39(0.89-2.17)$ & 1 \\
\hline Extremities & $3(0.4)$ & $71(32.5)$ & $102(38.3)$ \\
\hline \multirow{2}{*}{ OR $(95 \% \mathrm{CI})$} & $0.01^{*}(0.00-0.03)$ & 1 & \\
\hline & $0.01^{*}(0.00-0.02)$ & $0.67^{*}(0.46-0.97)$ & 1 \\
\hline Multiple fractures & $2(0.3)$ & $36(14.9)$ & $13(4.9)$ \\
\hline \multirow{2}{*}{ OR $(95 \% \mathrm{CI})$} & $0.02^{*}(0.00-0.06)$ & 1 & \\
\hline & $0.05^{*}(0.01-0.22)$ & $3.42^{*}(1.77-6.62)$ & 1 \\
\hline Unspecific trauma & $46(5.9)$ & $34(14.1)$ & $49(18.4)$ \\
\hline \multirow{2}{*}{ OR $(95 \% \mathrm{CI})$} & $0.38^{*}(0.24-0.61)$ & 1 & \\
\hline & $0.25^{*}(0.18-0.42)$ & $0.73(0.45-1.17)$ & 1 \\
\hline Burns & $11(1.4)$ & $21(8.7)$ & $3(1.1)$ \\
\hline Asphyxiation & $265(33.8)$ & 0 & 0 \\
\hline Others & $59(7.1)$ & $15(6.2)$ & $38(14.4)$ \\
\hline
\end{tabular}

*significant difference. 
fatal cases $(\mathrm{OR}=0.77,95 \% \mathrm{CI}: 0.53-1.13)$, respectively.

The proportion of extremities injury of the deaths $(0.4 \%)$ was significantly lower than the proportion of extremities injury of the serious injuries $(32.5 \%$, OR $=$ $0.01,95 \%$ CI: $0.00-0.03$ ), and of the moderate injuries $(38.3 \%, \mathrm{OR}=0.01,95 \%$ CI: $0.00-0.02)$, respectively. The proportion of extremities injury of the serious injuries was significantly lower than the proportion of extremities injury among the moderate injuries $(\mathrm{OR}=0.67$, 95\% CI: $0.46-0.97)$. The proportion of multiple fractures of the deaths $(0.3 \%)$ was significantly lower than the proportion of multiple fractures of the serious injuries $(14.9 \%, \mathrm{OR}=0.02,95 \% \mathrm{CI}: 0.00-0.06)$, and of the moderate injuries $(4.9 \%, \mathrm{OR}=0.05,95 \% \mathrm{CI}: 0.01$ 0.22 , respectively. The proportion of multiple fractures of the serious injuries was higher than the proportion of multiple fractures of the moderate injuries $(\mathrm{OR}=3.42$, 95\% CI: 1.77 - 6.62).

The proportion of unspecific trauma of the deaths $(5.9 \%)$ was significantly lower than the proportion of unspecific trauma of the serious injuries $(14.1 \%$, OR $=$ $0.38,95 \%$ CI: $0.24-0.61$ ), and of the moderate injuries $(18.4 \%, \mathrm{OR}=0.25,95 \%$ CI: $0.18-0.42)$, respectively. There was no difference in the proportion of unspecific trauma between the serious injuries and moderate injuries $(\mathrm{OR}=0.73,95 \%$ CI: 0.45 - 1.17).

\subsection{Risk Factor Analysis for Serious Injuries and Controls by a Case-Control Study}

Only records with values for all structural, medical assistance, personal, and behavior variables $(\mathrm{n}=370)$ were included in the estimation (Table 4). In the structural characteristics, completely collapsed of cases had 11.44 times (95\% CI: 6.86 - 19.08) the risk compared to controls. Most of the study subjects (cases: $94.8 \%$; controls: $88.8 \%$ ) were sleeping in the middle of the night in their houses. Individual lived alone at the time of earthquake of the cases $(10 \%)$ experienced a significantly higher proportion than those of the controls $(4 \%, \mathrm{OR}=2.67$, 95\% CI: 1.12 - 6.36). Of the cases, $78.3 \%$ had been trapped that was significantly higher than the proportion of been trapped of the controls $(12.4 \%, \mathrm{OR}=25.54,95 \%$ CI: 14.38 - 45.37). In the medical assistance characteristics, the proportion of trapped time within 6 hours were similar between the cases $(80.85 \%)$ and the controls $(80.65 \%$, OR $=1.01,95 \%$ CI: $0.36-2.83)$. The first medical care received after extrication within 8 hours for the cases $(78.7 \%)$ and the controls $(80.6 \%)$ were similar. The initial extrication and rescue work was most carried out by local inhabitants of the cases (92.6\%). This proportion was significantly higher than the controls $(41.9 \%)$ $(\mathrm{OR}=17.21,95 \%$ CI: 6.02 - 49.16).
In the personal characteristics, the cases contained a greater percentage of unemployment (19.2\%), illiteracy $(27.5 \%)$, and possession of cars with major disease $(12.5 \%)$ than the controls $(5.2 \%, \mathrm{OR}=7.17,95 \% \mathrm{CI}$ : $3.01-16.59 ; 5.2 \%$, OR $=11.47,95 \%$ CI: $5.10-25.80$; $3.2 \%, \mathrm{OR}=2.60,95 \% \mathrm{CI}: 1.20-5.67)$, respectively. The proportion of more than one victim in a family was higher in the cases than in the controls $(82.5 \%$ versus $12.4 \%$; OR $=33.30,95 \%$ CI: $18.23-60.85$ ). In the behavior and preparedness, there were lower prepared measures for disasters of the cases than of the controls, such as lower proportions of disaster drills $(5.0 \%$ versus $14.0 \%$; OR $=3.09,95 \% \mathrm{CI}: 1.26-7.57)$, putting heavier objects in low places $(5.8 \%$ versus $22.8 \%$; OR $=4.77$, $95 \%$ CI: $2.10-10.81)$, not putting objects in doorways $(6.7 \%$ versus $66.0 \%$; $\mathrm{OR}=27.18,95 \%$ CI: $12.66-58.32)$, preparedness of extinguishers $(8.3 \%$ versus $28 \%$; OR $=$ 10.39, 95\% CI: 5.26 - 20.52), and preparedness of flares ( $14.1 \%$ versus $56.9 \%$; OR $=3.47,95 \%$ CI: $1.95-6.16)$.

We put above significant variables into conditional logistic regression analyses. The results identified only four significant risk factors for the serious injuries (Table 5). The highest risk was being trapped ( $\mathrm{OR}=12.31$, $95 \%$ CI: $6.29-24.28$ ), followed by illiteracy (OR $=7.65$, $95 \%$ CI: $2.67-21.90)$, houses completely collapsed (OR = $4.55,95 \%$ CI: $2.26-9.16$ ), and lack of preparedness of flares $(\mathrm{OR}=2.50,95 \% \mathrm{CI}: 1.10-6.25)$.

\section{Discussion}

The age-specific proportions of fatal and non-fatal injuries victims were higher among the elderly $(65+$ years of age). These patterns reflected that although the elderly occupied $10 \%$ of the total population, injured seniors occupied about $37 \%$ of the total population. The distributions of the age-specific mortality and morbidity caused by the Chi-Chi earthquake were similar to the conditions of the Armenia earthquake, Northridge earthquake, and Hanshin-Awagi earthquake [19,21,29].

There were $89.2 \%$ of the seismic deaths were not admitted to the emergency department of hospitals. The asphyxiation and intracranial injury occupied $77 \%$ of caused deaths. These results imply incomplete or inadequate resuscitation, and control of hemorrhage before or during transportation. Aggressive and directed management of the pulmonary system coupled with prompt recognition and control of hemorrhaging due to associated injuries is essential for optimal patient outcome.

Higher crude odds ratios were observed for victims in completely collapsed houses in the deaths and the serious injuries groups. This suggests that the higher the house damage occurred, the higher the victim were casualty. Other studies also confirmed the risk presented by dilapidated 
Table 4. Characteristics of serious injuries (cases) and controls caused by the Chi-Chi earthquake, Nantou, Taiwan, 1999.

\begin{tabular}{|c|c|c|c|}
\hline Characteristic & Cases $(n=120)$ & Controls $(n=250)$ & OR $(95 \% \mathrm{CI})$ \\
\hline \multicolumn{4}{|c|}{ Structure characteristics completely collapsed ${ }^{*}$} \\
\hline No & 37 & 209 & 1 \\
\hline Yes & 83 & 41 & $11.44(6.86-19.08)$ \\
\hline \multicolumn{4}{|l|}{ Inside house } \\
\hline No & 4 & 5 & 1 \\
\hline Yes & 116 & 245 & $0.59(0.16-2.25)$ \\
\hline \multicolumn{4}{|l|}{ Sleep in house } \\
\hline No & 6 & 23 & 1 \\
\hline Yes & 110 & 222 & $1.90(0.75-4.80)$ \\
\hline \multicolumn{4}{|l|}{ Lived alone $^{*}$} \\
\hline No & 108 & 240 & 1 \\
\hline Yes & 12 & 10 & $2.67(1.12-6.36)$ \\
\hline \multicolumn{4}{|l|}{ Trapped $^{*}$} \\
\hline No & 26 & 219 & 1 \\
\hline Yes & 94 & 31 & $25.54(14.38-45.37)$ \\
\hline \multicolumn{4}{|l|}{$\begin{array}{l}\text { Medical assistance } \\
\text { trapped time }\end{array}$} \\
\hline$\leq 6 \mathrm{hr}$ & 76 & 25 & 1 \\
\hline $7-72 \mathrm{hrs}$ & 18 & 6 & $1.01(0.36-2.83)$ \\
\hline \multicolumn{4}{|c|}{$\begin{array}{l}\text { First medical care received } \\
\text { after extrication }\end{array}$} \\
\hline$\leq 8 \mathrm{hrs}$ & 74 & 25 & 1 \\
\hline $9-48 \mathrm{hrs}$ & 20 & 6 & $1.13(0.41-3.12)$ \\
\hline \multicolumn{4}{|l|}{ Rescuer $^{*}$} \\
\hline Self & 7 & 18 & 1 \\
\hline Others & 87 & 13 & $17.21(6.02-49.16)$ \\
\hline \multicolumn{4}{|c|}{ Personal characteristics } \\
\hline \multicolumn{4}{|l|}{ Sex } \\
\hline Male & 48 & 116 & 1 \\
\hline Female & 72 & 134 & $1.30(0.83-2.02)$ \\
\hline \multicolumn{4}{|l|}{ Unemployment $^{*}$} \\
\hline No & 97 & 242 & 1 \\
\hline Yes & 23 & 8 & $7.17(3.01-16.59)$ \\
\hline \multicolumn{4}{|l|}{ Illiteracy $^{*}$} \\
\hline No & 87 & 242 & 1 \\
\hline Yes & 33 & 8 & $11.47(5.10-25.80)$ \\
\hline
\end{tabular}




\section{Continued}

Car before the earthquake*

$\begin{array}{lr}\text { No } & 105 \\ \text { Yes } & 15\end{array}$

237

Other family hurt ${ }^{*}$

No

Yes

Behavior and preparedness

drill for disaster before

the earthquake*

\section{Yes}

No

Evacuation road

Yes

No

Put heavier objects

in low places*

Yes

No

Put objects in the doorway*

No

Yes

Preparedness of extinguishers ${ }^{*}$

Yes

No

Preparedness of flares*

Yes 17

No 103

No. of export escapes

$\leq 1$

$>1$
13

05

(1)

*significant difference.

buildings demonstrated in previous studies [12,19,35]. Forensic evidence indicates that intracranial and internal injuries for the crush of the head and trunk, and asphyxiation caused by acute obstructive pulmonary accounted for $77 \%$ of the deaths in the completely houses. These reflect that the primary cause of death was the complete collapse of houses. Intracranial, spine, intrathoracic, and visceral injuries as injuries to vital organs cause casualties resulting from earthquake injuries.

Comparing of the body sites of injuries, the proportion of multiple fractures and burns were higher of the serious injuries than of the moderate injuries, respectively. These results imply that the more the sites of injuries which occurred, the greater the severity of injuries occurred. The victims with spine and back injuries were fewer than the victims with trunk injuries in all the 3 study groups. Maruo et al. has demonstrated that if the patients are standing or sitting at the time of injury, the most frequently observed fractures are those of the vertebral column and if the patients are lying in supine or lateral positions at 
Table 5. Results of conditional logistic regression analyses, Chi-Chi earthquake, Nantou, Taiwan, 1999.

\begin{tabular}{|c|c|c|}
\hline \multirow{2}{*}{ Characteristic } & \multirow{2}{*}{$\begin{array}{c}\text { Univariate estimate } \\
\text { OR }(95 \% \mathrm{CI})\end{array}$} & \multirow{2}{*}{$\begin{array}{c}\text { Adjusted estimate } \\
\text { OR }(95 \% \mathrm{CI})\end{array}$} \\
\hline & & \\
\hline \multicolumn{3}{|c|}{$\begin{array}{l}\text { Structure characteristics } \\
\text { completely collapsed }^{*}\end{array}$} \\
\hline No & 1 & 1 \\
\hline Yes & $11.44(6.86-19.08)$ & $4.55(2.26-9.16)$ \\
\hline \multicolumn{3}{|l|}{ Alone } \\
\hline No & 1 & 1 \\
\hline Yes & $2.67(1.12-6.36)$ & $0.9(0.23-3.46)$ \\
\hline \multicolumn{3}{|l|}{ Trapped ${ }^{*}$} \\
\hline No & 1 & 1 \\
\hline Yes & $25.54(14.38-45.37)$ & $12.31(6.11-24.83)$ \\
\hline \multicolumn{3}{|c|}{ Personal characteristics } \\
\hline \multicolumn{3}{|l|}{ Illiteracy $^{*}$} \\
\hline No & 1 & 1 \\
\hline Yes & $11.47(5.10-25.80)$ & $7.65(2.67-21.90)$ \\
\hline \multicolumn{3}{|c|}{$\begin{array}{l}\text { Major disease car } \\
\text { before the earthquake }\end{array}$} \\
\hline No & 1 & 1 \\
\hline Yes & $2.60(1.20-5.67)$ & $0.97(0.33-2.80)$ \\
\hline \multicolumn{3}{|c|}{$\begin{array}{l}\text { Behavior and preparation } \\
\text { drill for disaster before } \\
\text { the earthquake }\end{array}$} \\
\hline Yes & 1 & 1 \\
\hline No & $3.09(1.26-7.57)$ & $1.72(0.50-5.94)$ \\
\hline \multicolumn{3}{|l|}{$\begin{array}{l}\text { Put heavier objects } \\
\text { in low places }\end{array}$} \\
\hline Yes & 1 & 1 \\
\hline No & $4.77(2.10-10.81)$ & $1.66(0.47-5.88)$ \\
\hline \multicolumn{3}{|c|}{ Put objects in the doorway } \\
\hline No & 1 & 1 \\
\hline Yes & $27.18(12.66-58.32)$ & $1.53(0.48-4.88)$ \\
\hline \multicolumn{3}{|c|}{ Preparedness of extinguishers } \\
\hline Yes & 1 & 1 \\
\hline No & $10.39(5.26-20.52)$ & $1.34(0.45-3.99)$ \\
\hline \multicolumn{3}{|c|}{ Preparedness of flares* } \\
\hline Yes & 1 & 1 \\
\hline No & $3.47(1.95-6.16)$ & $2.50(1.1-6.25)$ \\
\hline
\end{tabular}

*significant difference. 
the time of the earthquake, most fractures are those of the pelvis and thoracic cage skeleton [46]. Most of he study subjects were sleeping in the middle of the night in their houses from the interview results. Therefore, our study strongly agreed with the findings of Maruo et al. The victims with upper extremities injuries were fewer than the victims with lower extremities injuries in all the 3 study groups. Naghi et al. suggested that the injuries of upper or lower extremities may have to do with the time of day that the earthquake occurred. In the dark, respondents cannot see the objects that they trip or fall over and it is easy to injury the lower extremities, whereas in the light, victims were more likely to be upright and be struck by falling objects and it is easy to injury the upper limbs [16]. Such a relation was also observed in our study cases.

The cases seemed to be lower socioeconomic status such as, illiteracy, more unemployment, and possession of major disease cars than the controls. The illiteracy showed to be the predominant odd ratio of socioeconomic status compared to the controls. Owing to the lower socioeconomic status, the cases had poor safety knowledge and preparedness, such as disaster drills, putting heavier objects in low places, not putting objects in doorways, preparedness of extinguishers, and preparation for flares for the disasters expectantly. More than one victim in a family was higher of the study cases than of the controls. The sign implied that there was a significant family cluster in the serious injuries group.

In the conditional logistic regression analyses, the results clearly demonstrate that been trapped, completely collapsed houses, illiteracy, and no flares preparation for disasters were the most important risk factors. These findings implied the trapped and completely collapsed as the structure characteristics, illiteracy as the personal characteristic, and unprepared the flares as the preparation characteristic that all could increase the risk of serious injury in the 1999 Chinese Taipei earthquake. Liao et $a l$. and Ellidokuz et al. indicated that poor seismic capacity was the major factor that caused great loss of lives $[13,35]$. Osaki et al., and Peek-Asa et al. implied older adults, physical disabilities, and completely destroyed dwellings could increase the mortality among people [21, 47]. Chou et al., Doocy et al., and Mahue-Giangreco et al. demonstrated that health and socioeconomic statuses were the most relevant factors to earthquake injury and mortality $[22,23,48]$. The low socioeconomic status of victim was also a risk factor of PTSD after the earthquakes. Seplaki et al. indicated the low socioeconomic status reported higher levels of depressive symptoms [40]. Chen et al. indicated the low educational level was a risk factor of psychological outcome of 1999 Chinese Taipei earthquake survivors [42]. Our study suggests that poor earthquake resistant building and lower socioeconomic status are both related to the serious injuries among people. Literacy education is a basic method to enlarge the knowledge and improve the occupational skill. When an illiteracy is educated to be a literacy, he will get more safety knowledge and be a proper behavior to prevent and prepare for the disasters.

After the 1999 Chinese Taipei earthquake, the Central Government established the institution "The Chi-Chi Earthquake Post-Disaster Reconstruction Commission" that utilized several reconstructing policies such as urban planning, new community construction, and implementation of disaster prevention, rescue, and emergency medical services. After the practice of reconstruction, there were many improvements in the disaster areas such as, the percentage of reinforced concrete area increased from $93.78 \%$ in 1997 to $99.17 \%$ in 2010 , the percentage of illiterate population decreased from $5.71 \%$ in 1997 to $1.98 \%$ in 2010, and the number of ambulances increased from 12 in 1997 to 29 in 2010 [49].

This study was limited by the sample selection. The number of fatalities and hospitalizations comprised a small proportion of the overall number of injuries. These diverse reports demonstrate the difficulty in determining the incidence of injury following a major disaster.

\section{Conclusion}

Physical injuries are correlated with house collapse and victim behavior at the time of earthquake impact. This study suggested that improvements in anti-seismic construction, head protection, and literacy education could decrease the effect of disaster. Further, using a flashlight to see in the dark, and moving slowly rather than running should be rigorously recommended as common-sense responses.

\section{Acknowledgements}

This work was supported by grant MOIS 902031 from the Architecture and Building Research Institute Ministry of Interior.

\section{REFERENCES}

[1] B. S. Huang, K. C. Chen, W. G. Huang, J. H. Wang, D. M. Chang, R. D. Huang, H. C. Chiu and C. C. P. Tsai, "Characteristics of Strong Ground Motion across a Thrust Fault Tip from the September 21 1999, Chi-Chi, Chinese Taipei Earthquake," Geophysical Research Letters, Vol. 27, No. 17, 2000, pp. 2729-2732. doi:10.1029/2000GL011396

[2] Chi-Chi Earthquake Post-Disaster Reconstruction Commission, "Important Statistics about the Chi-Chi Earthquake Disaster," 2001. http://www.921erc.gov.tw (in Chinese)

[3] R. A. Page, J. A. Blume and W. B. Joyner, "Earthquake 
Shaking and Damage to Buildings," Science, Vol. 189, No. 4203, 1975, pp. 601-608. doi:10.1126/science.189.4203.601

[4] D. Alexander, "Death and Injury in Earthquakes," Disasters, Vol. 9, No. 1, 1985, pp. 57-60. doi:10.1111/j.1467-7717.1985.tb00911.x

[5] Y. H. Liao, L. C. Huang, J. H. Huang, S. F. Lin, M. Shen, C. H. Lin, C. C. Chang, Y. J. Hong, I. L. Lee, Y. Y. Guo and C. T. Yang, "Building Collapse and Human Deaths Resulting from the Chi-Chi Earthquake in Taiwan, September 1999," Archives of Environmental Health, Vol. 58, No. 9, 2003, pp. 572-578. doi:10.3200/AEOH.58.9.572-578

[6] Z. C. Moh and R. N. Hwang, "1999 Chi Chi Earthquake of Taiwan," Bulletin of the Seismological Society of America, Vol. 93, No. 1, 2003, pp. 386-396.

[7] E. Gutierrz, F. Taucer, T. De Groeve and D. H. A. AlKhudhairy, "Analysis of Worldwide Earthquake Mortality Using Multivariate Demographic and Seismic Data," American Journal of Epidemiology, Vol. 161, No. 12, 2005, pp. 1151-1158. doi:10.1093/aje/kwi149

[8] R. I. Glass, J. J. Urrutia, S. Sibony, H. Smith, B. Garcia and L. Rizzo, "Earthquake Injuries Related to Housing in a Guatemalan Village," Science, Vol. 197, No. 4304, 1977, pp. 638-643. doi:10.1126/science. 197.4304.638

[9] M. F. Lechat, "Disasters and Public Health," Bulletin of the World Health Organization, Vol. 57, No. 1, 1979, pp. 11-17.

[10] M. De Bruycker, D. Greco, I. Annino, M. A. Stazi, N. De Ruggiero, M. Triassi, Y. P. De Kettenis and M. F. Lechat, "The 1980 Earthquake in Southern Italy: Rescue of Trapped Victims and Mortality," Bulletin of the World Health Organization, Vol. 61, No. 6, 1983, pp. 1021-1025.

[11] A. Pomons, "The Spitak (Armenia, USSR) Earthquake: Residential Building Typology and Seismic Behavior," Disasters, Vol. 14, No. 2, 1990, pp. 89-114. doi:10.1111/j.1467-7717.1990.tb01051.x

[12] C. C. Chan, Y. P. Lin, H. H. Chen, T. Y. Chang, T. J. Cheng and L. S. Cheng, "A Population-Based Study on the Immediate and Prolonged Effects of the 1999 Taiwan Earthquake on Mortality," Annals of Epidemiology, Vol. 13, No. 7, 2003, pp. 502-508. doi:10.1016/S1047-2797(03)00040-1

[13] Y. H. Liao, S. F. Lin, W. H. Liao, J. H. Huang, M. Shen and C. H. Lin, "Deaths Related to Housing in 1999 Chi-Chi, Taiwan, Earthquake," Safety Science, 43, Vol. 43, No. 1, 2005, pp. 29-37. doi:10.1016/j.ssci.2004.11.002

[14] C. Peek-Asa, M. R. Ramirez, K. Shoaf, H. Seligson and J. F. Kraus, "GIS Mapping of Earthquake-Related Deaths and Hospital Admissions from the 1999 Northridge, California Earthquake," Annals of Epidemiology, Vol. 10, No. 1, 2000, pp. 5-13. doi:10.1016/S1047-2797(99)00058-7

[15] N. J. Liang, Y. T. Shih, F. Y. Shih, H. M. Wu, H. J. Wang, S. F. Shi, M. Y. Liu and B. B. Wang, "Disaster Epidemiology and Medical Response in the Chi-Chi Earthquake in Taiwan," Annals of Emergency Medicine, Vol. 38, No. 5, 2001, pp. 549-555. doi:10.1067/mem.2001.118999

[16] T. M. Naghi, K. Kambiz, J. M. Shahriar, T. Afshin, S. K.
Reza, P. Behnam and A. H. Bahador, "Musculoskeletal Injuries Associated with Earthquake," International Journal of Care Injured, Vol. 36, No. 1, 2005, pp. 27-32.

[17] J. Wen, Y. K. Shi, Y. P. Li, I. Wang, I. Chen, Z. Gao and L. Li, "Risk Factors of Earthquake Inpatient Death: A Case Control Study," Critical Care, Vol. 13, No. 1, 2009, p. R24. doi:10.1186/cc7729

[18] S. E. Health, P. H. Kass, A. M. Beck and L. T. Glickmam, "Human and Pet-Related Risk Factors for Household Evacuation Failure during a Natural Disaster," American Journal of Epidemiology, Vol. 153, No. 7, 2001, pp. 659665. doi:10.1093/aje/153.7.659

[19] C. Peek-Asa, J. F. Kraus, L. B. Bourque, D. Vimalachandra and J. A. Yu, "Fatal and Hospitalized Injuries Resulting from the 1994 Northridge Earthquake," International Journal of Epidemiology, Vol. 27, No. 3, 1998, pp. 459-465. doi:10.1093/ije/27.3.459

[20] K. I. Shoaf, L. H. Nguyen, H. R. Sareen and L. B. Bourque, "Injuries as a Result of California Earthquakes in the Past Decade," Disasters, Vol. 22, No. 3, 1998, pp. 218-235. doi:10.1111/1467-7717.00088

[21] Y. Osaki and M. Minowa, "Factors Associated with Earthquake Deaths in the Great Hanshin-Awaji Earthquake, 1995," American Journal of Epidemiology, Vol. 153, No. 2, 2001, pp. 153-156. doi:10.1093/aje/153.2.153

[22] Y. J. Chou, N. Huang, C. H. Lee, S. L. Tsai, L. S. Chen and H. J. Chang, "Who Is at Risk of Death in an Earthquake?" American Journal of Epidemiology, Vol. 160, No. 7, 2004, pp. 688-695. doi:10.1093/aje/kwh270

[23] S. Doocy, A. Danieis and D. Aspilcueta, "Mortality and Injury Following the 2007 Ica Earthquake in Peru," American Journal of Disaster Medicine, Vol. 4, No. 1, 2009, pp. 15-22.

[24] M. De Bruycker, D. Greco and M. Lechat, "The 1980 Earthquake in Southern Italy Morbidity and Mortality," International Journal Association, Vol. 14, No. 1, 1985, pp. 113-117.

[25] M. F. Lechat, "The Epidemiology of Health Effects of Disasters," Epidemiologic Reviews, Vol. 12, 1990, pp. 192-197.

[26] H. K. Armenian, E. K. Noji and A. P. Oganesian, “A Case-Control Study of Injuries Arising from the Earthquake in Armenia," Bulletin of the World Health Organization, Vol. 70, No. 2, 1992, pp. 251-257.

[27] M. C. Roces, M. E. White, M. M. Dayrit and M. E. Durkin, "Risk Factors for Injuries Due to the 1990 Earthquake in Luzon, Philippines," Bulletin of the World Health Organization, Vol. 70, No. 4, 1992, pp. 509-514.

[28] E. K. Noji, H. K. Armenian and A. Oganessian, "Issues of Rescue and Medical Care Following the 1988 Armenian Earthquake," International Journal of Epidemiology, Vol. 22, No. 6, 1993, pp. 1071-1076. doi:10.1093/ije/22.6.1070

[29] H. K. Armenian, A. M. Konian, E. K. Noji and A. P. Hovanesian, "Deaths and Injuries Due to the Earthquake in Armenia: A Cohort Approach," International Journal of Epidemiology, Vol. 26, No. 4, 1997, pp. 806-813. doi:10.1093/ije/26.4.806 
[30] D. C. Angus, E. A. Pretto, J. I. Abrams, N. Ceciliano, Y. Watoh, B. Kirimitili, A. Certug and L. K. Comfort, "Epidemiologic Assessment of Mortality, Building Collapse Pattern, and Medical Response after the 1992 Earthquake in Turkey," Prehospital and Disaster Medicine, Vol. 12, No. 2, 1997, pp. 222-231.

[31] H. Tanaka, A. Iwai, J. Oda, Y. Kuwagata, T. Matsuoka, T. Shimazu and T. Yoshioka, "Overview of Evacuation and Transport of Patients Following the 1995 Hanshin-Awaji Earthquake," The Journal of Emergency Medicine, Vol. 16, No. 3, 1998, pp. 439-444. doi:10.1016/S0736-4679(98)00014-6

[32] Y. S. Wen, C. P. Hsu, T. C. Lin, D. Y. Yang and T. C. $\mathrm{Wu}$, "Chest Injuries Transferred to Trauma Centers after the 1999 Taiwan Earthquake," American Journal of Emergency Medicine, Vol. 18, No. 7, 2000, pp. 825-827. doi:10.1053/ajem.2000.18132

[33] W. T. Chiu, J. Arnold, Y. T. Shih, K. H. Hsiung, H. Y. Chi, C. H. Chiu and W. C. Tsai, "A Survey of International Urban Search-And-Rescue Teams Following the Ji Ji Earthquake," Disasters, Vol. 26, No. 1, 2002. pp. 85-94. doi:10.1111/1467-7717.00193

[34] K. T. Chen, W. J. Chen, J. Malilay and S. J. Twu, "The Public Health Response to the Chi-Chi Earthquake in Taiwan, 1999," Public Health Reports, Vol. 118, No. 6, 2003, pp. 493-499.

[35] H. Ellidokuz, R. Ucku, U. Y. Aydin and E. Ellidokuz, "Risk Factors for Death and Injuries in Earthquake: Cross-Sectional Study from Afyon, Turkey," Croat Medicine Journal, Vol. 46, No. 4, 2005, pp. 613-618.

[36] H. Kao and W. P. Chen, "The Chi-Chi Earthquake Sequence: Active, Out-of-Sequence Thrust Faulting in Taiwan," Science, Vol. 288, No. 5475, 2000, pp. 2346-2349. doi:10.1126/science.288.5475.2346

[37] Y. J. Chou, N. Huang, C. H. Lee, S. L. Tsai, J. H. Tsay and L. S. Chen, "Suicides after the 1999 Taiwan Earthquake," International Journal of Epidemiology, Vol. 32, No. 6, 2003, pp. 1007-1014. doi:10.1093/ije/dyg296

[38] C. Watanabe, J. Okumura, T. Y. Chiu and S. Wakai, "Social Support and Depressive Symptom among Displaced Older Adults Following the 1999 Taiwan Earthquake," Journal of Trauma Stress, Vol. 17, No. 1, 2004, pp. 63-67. doi:10.1023/B:JOTS.0000014678.79875.30

[39] C. M. Chang, K. M. Connor, T. J. Lai, L. C. Lee and J. R. T. Davidson, "Predicators of Posttraumatic Outcomes Following the 1999 Taiwan Earthquake," Journal of Nervous and Mental Disease, Vol. 193, No. 1, 2005, pp. 4046. doi:10.1097/01.nmd.0000149217.67211.ab

[40] C. L. Seplaki, N. Goldman, M. Weinstein and Y. H. Lin, "Before and after the 1999 Chi-Chi Earthquake: Traumatic Events and Depressive Symptoms in an Older Population," Social Science \& Medicine, Vol. 62, No. 12,
2006, pp. 3121-3132.

doi:10.1016/j.socscimed.2005.11.059

[41] F. H. Chou, H. C. Wu, P. Chou, C. Y. Su, K. Y. Tsai, S. S. Chao, M. C. Chen, T. T. P. Su, W. J. Sun and W. C. Ou-Yang, "Epidemiologic Psychiatric Studies on PostDisaster Impact among Chi-Chi Earthquake Survivors in Yu-Chi, Taiwan," Psychiatry and Clinical Neuroscience, Vol. 61, No. 4, 2007, pp. 370-378. doi:10.1111/j.1440-1819.2007.01688.x

[42] C. H. Chen, H. K. Tan, L. R. Liao, H. H. Chen, C. C. Chan, J. J. S. Cheng, C. Y. Chen, T. N. Wang and M. L. $\mathrm{Lu}$, "Long-Term Psychological Outcome of 1999 Taiwan Earthquake Survivors: A Study of a High-Risk Sample with Property Damage," Comprehensive Psychiatry, Vol. 48, No. 3, 2007, pp. 269-275. doi:10.1016/j.comppsych.2006.12.003

[43] Y. P. Liaw, P. W. Wang, C. C. Huang, C. M. Chang and W. C. Lee, "The Suicide Mortality Rates between $1997-$ 1998 and 2000-2001 in Nantou County of Taiwan Following the Earthquake of September 21 in 1999," Journal of Forensic Sciences, Vol. 53, No. 1, 2008, pp. 199-202. doi:10.1111/j.1556-4029.2008.00592.X

[44] C. Y. Su, K. Y. Tsai, H. C. Chou, W. W. Ho, R. Liu and W. K. Lin, "A Three-Year-Follow-Up Study of the Psychosocial Predictors of Delayed and Unresolved Post Traumatic Stress Disorder in Taiwan Chi-Chi Earthquake Survivor," Psychiatry and Clinical Neuroscience, Vol. 64, No. 3, 2010, pp. 239-248. doi:10.1111/j.1440-1819.2010.02087.x

[45] C. H. Yang, S. Xirasagar, H. C. Chung, Y. T. Huang and H. C. Lin, "Suicide Trends Following the Taiwan Earthquake of 1999: Empirical Evidence and Policy Implications," Psychiatry and Clinical Neuroscience, Vol. 112, No. 6, 2005, pp. 442-448. doi:10.1111/j.1600-0447.2005.00603.x

[46] S. Maruo and M. Matumoto, "Spinal Fractures Resulting from the 1995 Great Hanshin Earthquake of the KobeOsaka Area of Japan,” Spinal Cord, Vol. 34, No. 7, 1996, pp. 382-386. doi:10.1038/sc.1996.69

[47] C. Peek-Asa, M. Ramirez, H. Seligson and K. Shoaf, "Seismic, Structural, and Individual Factors Associated with Earthquake Related Injury," Injury Prevention, Vol. 9, 2003, pp. 62-66. doi:10.1136/ip.9.1.62

[48] M. Mahue-Giangreco, W. Mack, H. Seligson and A. B. Bourque, "Risk Factors Associated with Moderate and Serious Injuries Attributable to the 1994 Northridge Earthquake, Los Angles, California," Annals of Epidemiology, Vol. 11, No. 5, 2001, pp. 347-357. doi:10.1016/S1047-2797(01)00220-4

[49] Nantou County Government, "The Statistical Abstract of Nantou County," Nantou County Government Press, Nantou, 2011. 


\section{Appendix}

Diagnostic categories and ICD codes for the earthquake injuries.

\begin{tabular}{cc}
\hline Diagnostic category & ICD code \\
\hline Asphyxiation & 994.7 \\
Fracture & $800-29$ \\
Early complication of trauma and & $958-9$ \\
unspecific injuries & Open wounds \\
Burns & $870-9,890-7$ \\
\hline
\end{tabular}

